\title{
JULGAMENTO FRACIONADO DO MÉRITO NO PROCESSO CIVIL BRASILEIRO
}

\author{
Dissertação de Mestrado
}

Orientador: Professor Titular Dr. José Rogerio Cruz e Tucci

UNIVERSIDADE DE SÃO PAULO

FACULDADE DE DIREITO

São Paulo - SP 


\section{RESUMO}

AMBRIZZI, Tiago Ravazzi. Julgamento fracionado do mérito no processo civil brasileiro. 2014. 223 páginas. Mestrado - Faculdade de Direito, Universidade de São Paulo, São Paulo, 2014.

O estudo analisa, à luz do direito positivo em vigor no Brasil, a possibilidade de emissão de sentenças parciais dentro de um mesmo processo, de modo a solucionar por etapas o objeto litigioso. Procura-se demonstrar que não se trata de novidade absoluta, já convivendo o sistema brasileiro de longa data com situações de fracionamento da resposta judiciária, possibilidade que ficou amplificada com as sucessivas alterações por que passou o Código de Processo Civil Brasileiro. Examinam-se e refutam-se os afirmados obstáculos que impediriam ou contraindicariam o uso da técnica, com a demonstração de ser ela, em verdade, uma imposição do modelo processual constitucional brasileiro. Examinam-se aspectos técnicos ligados ao uso da técnica, verificando-se, principalmente: (i) em quais modalidades de cumulação de pedidos e de sujeitos ela tem cabimento; (ii) se também é possível falar na apreciação por etapas dos diferentes fundamentos da ação e da defesa; (iii) se a emissão de sentença parcial é ato discricionário ou vinculado do juiz; (iv) qual o momento adequado para que o juiz delibere acerca do custo financeiro do processo; (v) se é possível a formação gradual da coisa julgada dentro de um mesmo processo. Por fim, procura-se harmonizar o sistema de recursos ao uso da técnica, fazendo-se rápida menção aos sistemas jurídicos de outros países e ao Projeto do Novo Código de Processo Civil, que contempla o instituto aqui tratado na figura do "Julgamento Antecipado Parcial do Mérito".

Palavras-chave: Julgamento fracionado do mérito - Sentenças parciais Desmembramento - Coisa julgada gradual - Capítulos de sentença 


\begin{abstract}
AMBRIZZI, Tiago Ravazzi. Fragmented judgement of merit in Brazilian civil procedure law. 2014. 223 pages. Master - Faculty of Law, University of São Paulo, São Paulo, 2014.

In the light of positive law in force in Brazil, this study analyses the possibility of partial judgements being given in relation to the same lawsuit, in order to settle litigation in stages. The study seeks to demonstrate that this is not an absolute novelty and that the Brazilian legal system has been accustomed for a long time to situations in which the judicial response is fragmented. This possibility has increased following the successive alterations undergone by the Brazilian Code of Civil Procedure. The obstacles alleged to prevent or counterindicate the use of this technique are examined and refuted, demonstrating that in truth the technique is an imposition of the Brazilian constitutional procedural model. An examination is made of the technical aspects related to the use of the technique, verifying in particular: (i) in which modes of joinder of claims and subjects it is admissible; (ii) if it is also possible for the different grounds for the suit and the defence to be examined in stages; (iii) if the giving of partial judgement is a discretionary or binding act of the judge; (iv) what is the appropriate moment for the judge to decide on the financial cost of the proceedings; (v) if it is possible for res judicata to be gradually formed within the same lawsuit. Finally an attempt is made to harmonize the appeal system with the use of the technique, referring rapidly to the legal systems of other countries and the Bill of Law for the New Code of Civil Procedure, which contemplates the institution dealt with here as "Partial Summary Judgement of Merit".
\end{abstract}

Keywords: Fragmented judgement of merit - Partial judgements - Dismemberment Gradual res judicata - Segmented judgement 


\section{SUMÁRIO}

CAPÍTULO I

1. Apresentação do objeto fundamental do estudo 1

2. Hipóteses de desmembramento do objeto litigioso .............................................

2.1 Desmembramento ditado por razões exclusivamente processuais .....................5

2.2 Procedimentos especiais marcados pela bifurcação do procedimento .................9

2.2.1 Ação de consignação em pagamento ........................................................ 9

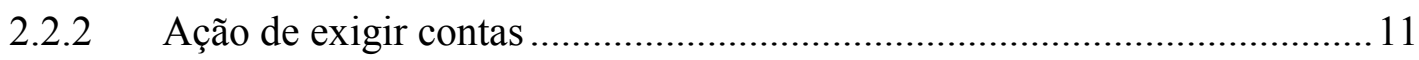

2.2.3 Ações de divisão e demarcação de terras particulares ................................ 14

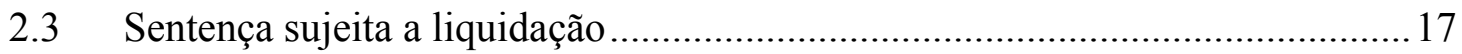

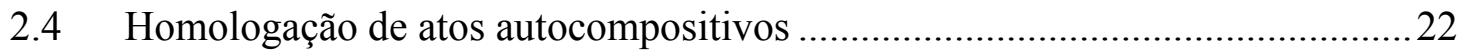

2.5 Pronúncia de prescrição ou decadência parcial ................................................. 31

2.6 Artigo 273, $\S 6^{\circ}$, do Código de Processo Civil (Lei 10.444/2002) ..................... 38

3. Novo conceito de sentença (Lei 11.232/2005) …...................................................50

3.1 Correntes doutrinárias sobre a configuração da sentença de mérito ..................56

3.2 Conceito legal de sentença terminativa .................................................... 70

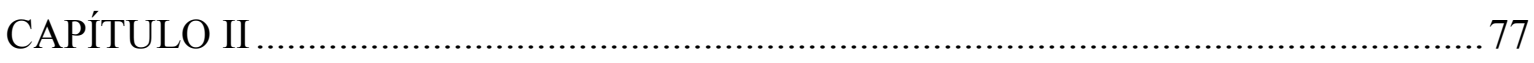

1. Afirmados óbices à admissibilidade da resolução fracionada do mérito ...................78

1.1 Princípio da unidade e unicidade da sentença ................................................... 78

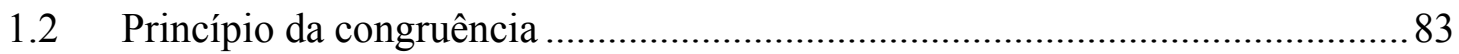

1.3 Alegada impossibilidade de formação gradual da coisa julgada....................... 88

1.4 Risco de desarmonia das decisões exaradas no mesmo processo ................... 101

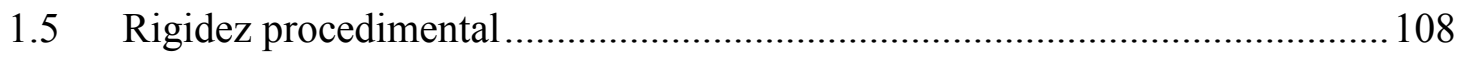


1.6 Tumulto no sistema recursal e sobrecarga dos tribunais

2. Fundamento constitucional e benefícios decorrentes do uso da técnica..................118

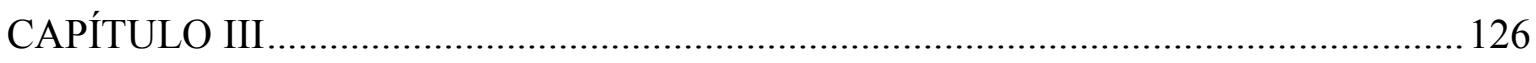

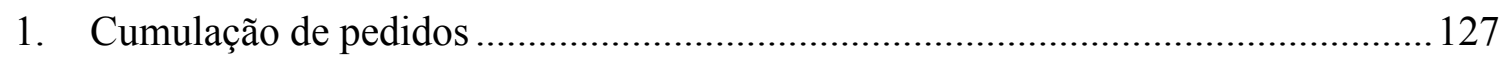

1.1 Casos de cumulação própria: cúmulos simples e sucessivo ...........................128

1.2 Casos de cumulação imprópria: cúmulo eventual (ou subsidiário) e cúmulo alternativo

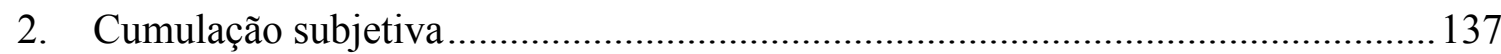

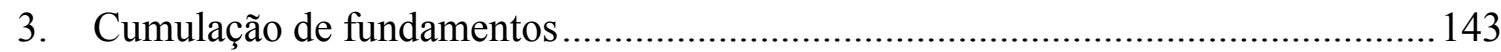

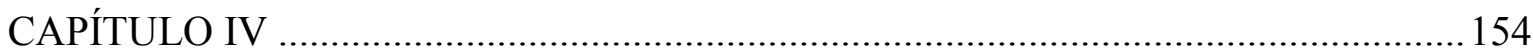

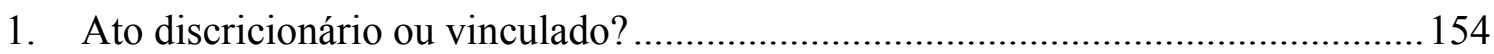

2. Momento de deliberar sobre o custo financeiro do processo ...................................159

3. Problemática recursal: tentativa de acomodação ................................................... 163

3.1 Estado da jurisprudência e fungibilidade recursal .......................................... 171

4. Coisa julgada, execução e prazo para ação rescisória............................................. 176

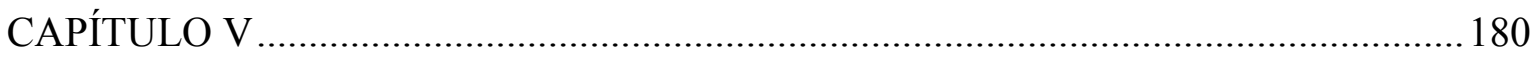

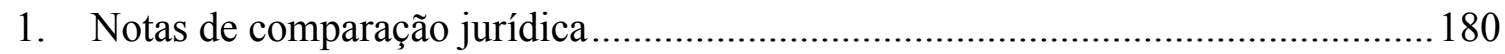

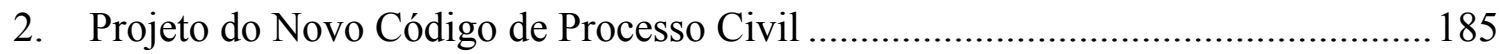

2.1 Anteprojeto apresentado ao Senado Federal pela Comissão de Juristas .......... 185

2.2 Substitutivo apresentado pelo Instituto Brasileiro de Direito Processual à

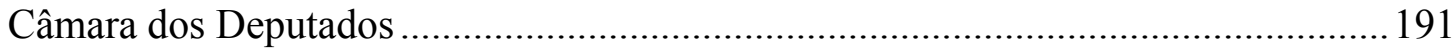

2.3 Versão do Substitutivo aprovado pela Câmara ................................................ 195

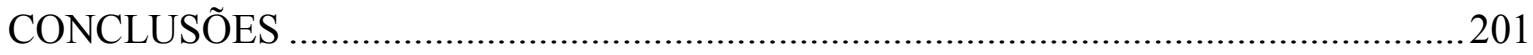

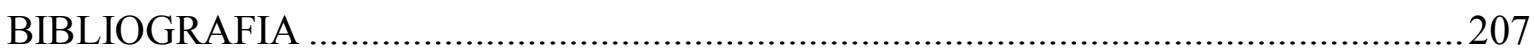




\section{CAPÍTULO I}

\section{Apresentação do objeto fundamental do estudo}

O presente estudo tem por objeto fundamental averiguar, do ponto de vista do direito positivo em vigor no Brasil, a possibilidade de ocorrer a cisão do julgamento do mérito, mediante a emissão de pluralidade de decisões dentro de uma única relação processual, cada qual num estágio procedimental próprio e tendente a solucionar, em caráter definitivo, parte do objeto litigioso.

A indagação diz respeito àqueles processos cujo objeto litigioso seja complexo (por motivo de cumulação inicial ou ulterior de demandas) ou então passível de fracionamento (em virtude da natureza do bem da vida postulado ao Estado-Juiz, que não raro é suscetível de divisão). Seria lícito ao juiz em casos tais promover o desmembramento da prestação jurisdicional definitiva, com a sua entrega em etapas? Ou, como diz Silas Dias de Oliveira Filho, em excelente definição do instituto, "julgar de forma fatiada o objeto litigioso, tão logo haja demandas maduras e prontas a tanto, prosseguindo-se o processo somente em relação àquelas que ensejassem maior dilação probatória"? ${ }^{1}$

Embora haja intuitiva conexão entre os temas, é importante consignar que não estamos nos referindo, aqui, à aplicação da teoria dos capítulos de sentença, que sugere a realização de cortes ideológicos dentro de uma decisão formalmente única, com vistas à identificação e isolamento dos diversos capítulos autônomos encontrados na sua parte dispositiva. $^{2} \mathrm{O}$ que queremos perquirir é se o juiz, dentro do processo civil individual

${ }^{1}$ OLIVEIRA FILHO, Silas Dias de. Julgamento fracionado do mérito e suas implicações no sistema recursal. Tese (Mestrado em Direito Processual) - Faculdade de Direito, Universidade de São Paulo, São Paulo, 2013, pp. 8-9.

${ }^{2}$ Como observa Cândido Rangel Dinamarco, a teoria dos capítulos de sentença se constrói sobre a pluralidade de capítulos encontrados no decisório. É sobre o dispositivo que o corte deve ser feito, pois é nele - e não na fundamentação - que reside a resposta jurisdicional à pretensão deduzida, vale dizer, o preceito imperativo que, acolhendo ou rejeitando a demanda, repercutirá na vida dos litigantes, com aptidão para ficar alcançado pelo manto da coisa julgada (DINAMARCO, Cândido Rangel. Capítulos de sentença. São Paulo: Malheiros, 2002, pp. 11 e 58). Reconhece o autor, porém, que por vezes também a cisão ideológica da fundamentação poderá trazer utilidades ao intérprete. É o que se dá, por exemplo, com a identificação e separação dos diversos fundamentos de certo acórdão, que poderão ensejar, conforme a natureza constitucional ou federal das questões resolvidas, recurso extraordinário ou especial (Capítulos de sentença, cit., p. 33). 
brasileiro, pode executar um corte real no objeto litigioso, com a fragmentação da resposta jurisdicional de mérito em mais de uma etapa, vale dizer, mediante pronunciamentos formalmente autônomos uns em relação aos outros, conforme se depare com o amadurecimento precoce de parte da demanda frente ao objeto remanescente.

A pergunta parece ser pertinente. Por influência da primitiva dicção do artigo 162, § $1^{\circ}$, do Código de Processo Civil - que, conceituando sentença como o ato que põe fim ao processo, eliminava em tese a possibilidade de múltiplas sentenças serem exaradas numa mesma relação processual -, tradicionalmente sempre se sustentou que o mérito havia de ser enfrentado e decidido em sua integralidade numa única ocasião, no ato final e culminante do procedimento cognitivo.

Eis aí a ideia de unidade e unicidade da sentença: todas as pretensões trazidas para acertamento judiciário devem receber resposta simultânea, esgotando-se em momento único o thema decidendum.

Com efeito, ao estatuir a sentença como ato final do processo (CPC, art. $162, \S 1^{\text {o }}$, em sua redação original) e, ainda, atribuir a ela a apreciação das "questões de fato e de direito" (CPC, art. 458, II) e o juízo sobre o acolhimento ou rejeição do pedido do autor (CPC, art. 459, caput), o Código teria vetado a definição progressiva do objeto litigioso. Simples ou complexo, vale dizer, caracterizado ou não pela acumulação de diferentes demandas, o objeto litigioso haveria de ser decidido em pronunciamento único (sentença), jamais gradualmente. ${ }^{3}$

Aliás, diga-se de passagem que a sentença não apenas deveria concentrar a decisão sobre o objeto litigioso, ou seja, da questão principaliter. Segundo a opinião corrente, a solução das questões de mérito, antecedentes lógicos do preceito imperativo a ser emitido na parte dispositiva, também seria uma exclusividade da sentença.

${ }^{3}$ Emblemática a esse respeito a lição de Moacyr Amaral Santos: "Tendo-se formado processo cumulativo, o julgamento antecipado somente pode verificar-se quando admissível para todas as lides que nele se cumulam. Assim, por exemplo, no caso de processo com reconvenção, caberá julgamento antecipado se a ação e a reconvenção estiverem em condições de ser julgadas antecipadamente. Aquela ou esta não preencha tais condições e reclame prosseguimento do processo, isso dar-se-á para que ambas as lides sejam julgadas pela mesma sentença, em audiência." (SANTOS, Moacyr Amaral. Primeiras Linhas de Direito Processual Civil. $2^{\circ}$ Vol. $3^{\text {a }}$ Ed. S. Paulo: Saraiva, 1977, p. 231). 
Assim, por exemplo, seria vedado ao juiz, na decisão de saneamento, afastar a prescrição suscitada pelo réu como causa extintiva do crédito perseguido pelo autor, determinando a abertura da instrução para a averiguação das demais matérias alegadas pela defesa (v.g., nulidade do contrato). Da mesma forma, pleiteado o despejo do réu do imóvel locado por duplo fundamento - inadimplemento dos aluguéis e desvirtuação do uso do bem -, não poderia o juiz, mesmo que provada de plano a inveracidade da primeira causa de pedir, repeli-la em saneador. Se assim procedesse, estaria, indevidamente, cindindo a solução das questões de mérito, reservada por lei à fundamentação da sentença (CPC, art. 458, II), e consequentemente malferindo o princípio da unicidade da sentença. ${ }^{4}$

Retornando à solução do mérito propriamente dito, o fato é que a lei, em diversas disposições, parece efetivamente induzir àquela conclusão, no sentido de vedar ao juiz a apreciação gradual dos diferentes pedidos, mediante a sua decisão em mais de um pronunciamento, conforme a maturação precoce de uma ou algumas das pretensões frente às demais. Afora os já referidos artigos 162, $\S 1^{\circ}, 458$ e 459, todos do Código de Processo Civil, poderiam ser invocados, em reforço àquela orientação, entre outros: a) o artigo 318, do Código, que sintomaticamente prevê que "Julgar-se-ão na mesma sentença a ação e a reconvenção"; b) o artigo 61, que determina o julgamento simultâneo da demanda principal e da oposição interventiva; c) os artigos 76 e 80, que preveem o julgamento simultâneo da ação principal e da denunciação da lide e do chamamento ao processo,

${ }^{4}$ Opõe-se a tal cisão no exame dos fundamentos da demanda ou da defesa Cândido Rangel Dinamarco, tachando de nula decisão com esse teor: "Diferente da divisão da sentença em capítulos é a cisão do julgamento, consistente em antecipar a decisão de alguma questão de mérito suscitada pelas partes, pronunciando-se o juiz sobre ela antes de proferir sentença. Essa prática é absolutamente contrária ao sistema, porque todas as questões relacionadas com o mérito devem ser julgadas em um ato só, como emerge do comando contido no art. 459 do Código de Processo Civil. É na sentença que o juiz acolhe ou rejeita, no todo ou em parte, o pedido formulado pelo autor (art. 459). Essa prática transgride também o disposto no art. 458, inc. II, do Código de Processo Civil, segundo o qual é na motivação da sentença que o juiz deve examinar as questões relativas ao meritum causae. Tal é o princípio da unidade da sentença, que só pode ser contrariado quando uma específica norma de direito o autorizar. (...) Diante do que é disposto no art. 295, inc. IV, e do art. 269, inc. IV do Código de Processo Civil, quando no curso do processo o juiz se vir diante da alegação de prescrição ou decadência, deduzida pelo réu, ele deve tomar uma dessas atitudes: a) ou reputa que uma dessas causas extintivas está presente e extingue desde logo o processo (art. 295, inc. IV), ou b) deixa de acolhê-la no momento e difere seu pronunciamento para o momento de sentenciar. Se rejeitar desde logo a alegação, ele estará cindindo indevidamente o julgamento de mérito, sendo nula essa decisão." (DINAMARCO, Cândido Rangel. Instituições de Direito Processual Civil. Vol. III. São Paulo: Malheiros, 2001, pp. 668-669). No mesmo sentido: MUNHOZ DA CUNHA, Alcides A. "Sentenças interlocutórias desafiando apelação". Revista de Processo, Vol. 185, Julho de 2010, pp. 211 e seguintes; BONÍCIO, Marcelo José Magalhães. "Notas sobre a tutela antecipada 'parcial' na nova reforma do Código de Processo Civil". Revista dos Tribunais, Vol. 808, Fevereiro de 2003, pp. 72 e seguintes; TEIXEIRA, Guilherme Puchalski. "Sentenças objetivamente complexas: impossibilidade do trânsito em julgado parcial". Revista de Processo, Vol. 162, Agosto de 2008, pp. 228 e seguintes. 
respectivamente; d) o artigo 330, do Código, que, ao regular o instituto do julgamento antecipado da lide, não faz nenhuma observação ou ressalva no sentido de excepcionar o princípio da unicidade e, assim, permitir expressamente a resolução parcial do meritum causae $^{5}$; e) o artigo 162, $\S 2^{\circ}$, do Código, que atribui às decisões interlocutórias a tarefa de solucionar pura e simplesmente questões incidentes, reservando ao ato final, contrario sensu, a definição de todo o objeto litigioso. ${ }^{6}$

Some-se a isso que o sistema admite a cumulação de demandas - e também a sua reunião, na forma do artigo 105 do Código - tendo em vista não apenas a economia processual, mas também com o objetivo de assegurar que diferentes pretensões, em geral ligadas por certa carga de conexidade, recebam julgamentos coerentes e harmônicos entre si. $^{7}$ Pleiteada a indenização de danos materiais e morais decorrentes de um mesmo acidente de trânsito, a cumulação ou reunião, teoricamente, elimina o risco de conflito lógico entre os diferentes capítulos de mérito: em tese, o réu não será (i) condenado ao pagamento dos danos materiais ao autor e, ao mesmo tempo, (ii) liberado de arcar com a indenização moral sob o fundamento - incompatível com a motivação do primeiro capítulo - de que não causou o acidente. De duas, uma: ou o réu causou o acidente e, sendo assim, pode vir a responder por todos os danos, desde que configurados e demonstrados; ou ele não o causou

5 “Julgar antecipadamente a lide não é apreciar parcialmente o seu mérito, em aspectos preliminares, mas de logo oferecer decisão que ponha fim ao processo, com solução do litígio." (CALMON DE PASSOS, José Joaquim. Comentários ao Código de Processo Civil. Vol. III. $6^{\text {a }}$ Ed. Rio de Janeiro: Forense, 1989, pp. 489-490).

${ }^{6}$ Como observa Heitor Vitor Mendonça Sica, o conceito de questão incidental, em verdade, é amplíssimo: "abarca todas as etapas necessárias para que o mérito da pretensão seja enfrentado, incluídas todas as questões de cunho processual pelas quais deve passar o juiz antes de chegar no mérito (prejudiciais ou não) e as próprias questões de fato e de direito que anteponham-se como fundamentos necessários para que se atinja uma solução final para a lide exposta em juízo. Logo se vê que essa categoria é bastante ampla e se subdivide em questões incidentais de mérito e questões incidentais processuais, e podem ser elas prejudiciais ou não.” (SICA, Heitor Vitor Mendonça. Preclusão processual civil. 2a Ed. S. Paulo: Atlas, 2008, p. 194). A rigor, portanto, o termo questão incidental não seria útil à distinção das questões resolvidas via interlocutória e via sentença. Porém, uma vez que as questões de mérito sejam reservadas para a sentença, o que parece efetivamente defluir do art. 458, II do CPC, a consequência lógica é a de restringir o alcance das decisões interlocutórias à solução das questões processuais ou de rito. Nesse exato sentido, adstringindo a finalidade das interlocutórias a tratar de "questões, controvérsias ou dúvidas que digam respeito ao procedimento e à relação processual": FREDERICO MARQUES, José. Manual de direito processual civil. Vol. 3. $3^{\text {a }}$ Ed. S. Paulo: Saraiva, 1978, pp. 38-39. Vai na mesma linha Teresa Arruda Alvim Wambier, para quem as interlocutórias "removem obstáculos à solução da lide, no curso do procedimento, criando condições para que seja proferida a decisão final", viabilizando a marcha do processo e preparando o ato final que é a sentença: WAMBIER, Teresa Arruda Alvim. Os agravos no CPC brasileiro. São Paulo: RT, 2000, pp. $385-$ 386.

${ }^{7}$ Cf. MALUF, Carlos Alberto Dabus. “Cumulação de ações no processo civil”. Revista de Processo, Vol. 17, Janeiro de 1980, pp. 61 e seguintes. O autor agrega ainda que, ao dispensar a conexão como requisito, como ocorria no Código de 1939, o Código em vigor facilitou a cumulação, fazendo-o com o propósito indisfarçável de impedir a proliferação de demandas. 
e, nessa medida, ambas as pretensões são improcedentes.

Trata-se de outro ponderável argumento a reforçar aquela premissa, no sentido de que a decisão em etapas das demandas cumuladas seria interdita. Cindir no tempo a resposta a cada um dos pedidos poderia dar ensejo a decisões conflitantes do ponto de vista das respectivas fundamentações, andando na contramão do que inspirou o legislador a permitir a aglutinação dentro de um mesmo processo.

No entanto, a questão não é tão simples assim. O mesmo sistema, que de um lado admite - e, segundo alguns, até mesmo facilita - a cumulação de pedidos, por outro lado sempre contemplou hipóteses de desmembramento e de paulatina redução desse objeto litigioso, aparentemente excepcionando, portanto, o princípio geral pelo qual a resposta a todas as pretensões há de ser dada em ato concentrado ao final do procedimento cognitivo. Por vezes esse desmembramento é ditado por razões exclusivamente processuais, sem implicar uma resposta de meritis à pretensão que vem a ser destacada do remanescente; em outras, ele ocorre por meio de uma resposta de mérito, apta à imunização com a coisa julgada material, em relação a parte do objeto litigioso, caracterizando nessa hipótese uma bifurcação do procedimento e um autêntico julgamento gradual do mérito.

É o que procuraremos exemplificar nos itens seguintes.

\section{Hipóteses de desmembramento do objeto litigioso}

\subsection{Desmembramento ditado por razões exclusivamente processuais}

A primeira situação que indica que o objeto litigioso não é exatamente indecomponível, podendo vir a ser desmembrado, tem a ver com razões de natureza exclusivamente processual.

Não é novidade alguma que o processo de conhecimento é organizado e estruturado com vistas à obtenção de um pronunciamento (sentença de mérito), por meio do qual o órgão jurisdicional deliberará acerca da demanda a ele submetida, declarando 


\section{CONCLUSÕES}

1. É tradicional a assertiva de que o sistema brasileiro não consente a segmentação da resposta jurisdicional cognitiva, determinando, consequentemente, que todas as questões de mérito e o próprio mérito sejam decididos em pronunciamento único, qual seja, a sentença final (princípio da unidade e unicidade da sentença).

2. A afirmação acima não pode, todavia, ser tomada como verdade absoluta. O sistema sempre contemplou hipóteses de desmembramento e de paulatina redução do objeto litigioso. Por vezes o desmembramento é ditado por razões exclusivamente processuais, sem implicar uma resposta de meritis à pretensão que vem a ser destacada do remanescente; em outras, ele ocorre por meio de uma resposta de mérito, apta à imunização com a coisa julgada material, porém circunscrita a parte do objeto litigioso, ficando caracterizada nessa hipótese uma bifurcação do procedimento e um autêntico julgamento gradual do mérito.

3. Julgamento do mérito por etapas já era identificado em alguns procedimentos especiais, caso da ação de consignação em pagamento, da ação de exigir contas e das ações de divisão e demarcação de terras particulares. Ocorria, também, mediante a prolação de sentença sujeita a ulterior liquidação, na homologação de atos autocompositivos parciais e na pronúncia de prescrição ou decadência parciais, em todas essas situações constatando-se solução gradual das questões principaliter, com paulatino enfrentamento do thema decidendum.

4. As alterações pelas quais passou o Código de Processo Civil parecem robustecer a possibilidade de segmentação da resposta definitiva de mérito. O artigo 273, §6 introduzido pela Lei 10.444/2002, embora (mal) inserido no artigo 273 do Código, não diz respeito a uma simples antecipação provisória de parte dos efeitos da tutela final. Permite que o juiz promova a resolução fracionada do mérito, emitindo desde logo decisão definitiva sobre o(s) pedido(s) incontroverso(s) e relegando a momento ulterior a solução do objeto litigioso restante, ainda pendente de maturação.

5. O atual conceito legal de sentença, atrelado exclusivamente ao conteúdo do ato - 
prescindindo, portanto, de sua localização na cadeia procedimental e de seu efeito de encerrar, ou não, a etapa cognitiva em primeiro grau -, abre a possibilidade para a prolação de mais de uma sentença dentro da fase de acertamento, eliminando por etapas o objeto litigioso. Tanto as sentenças definitivas quanto as terminativas são qualificadas, de acordo com o ordenamento em vigor, à luz do critério exclusivamente substancial.

6. As interlocutórias, na atual sistemática, devem ser qualificadas de modo residual, vale dizer, como atos que, diferentemente da sentença de mérito, nada definem em torno do objeto litigioso. Preparam caminho para a ulterior prolação da sentença, que no atual regime poderá ser mais de uma, a depender do pré-amadurecimento de parte do mérito frente ao restante.

7. Constata-se, todavia, a existência de certas interlocutórias que, mesmo sem tratar do objeto litigioso fixado pelas partes, deliberam e dão definição a certas pretensões surgidas no curso e em virtude do processo, irradiando efeitos para fora da relação processual. Essas decisões, qualificadas pela jurisprudência do Superior Tribunal de Justiça como interlocutórias de mérito, são passíveis de imunização com a coisa julgada material, mesmo pendente o processo no tocante ao julgamento do mérito propriamente dito.

8. O princípio da unicidade constitui decorrência lógica da oralidade e de seus subprincípios: aglutinada em momento único a discussão de todas as questões de fato e de direito, bem assim a produção das provas, o meritum causae também deveria, ao menos em tese, ser objeto de pronunciamento uno. No entanto, no processo civil brasileiro a oralidade apresenta-se sobremaneira mitigada, de tal sorte que não há sentido em continuar cultuando a ideia de unicidade de sentença e rechaçando de antemão a possibilidade de entrega fracionada da prestação jurisdicional.

9. As resoluções parciais de mérito não ofendem o princípio da congruência. Nelas o Estado-Juiz define uma fração do objeto litigioso, deixando calculadamente para depois a análise das pretensões remanescentes, em relação às quais ainda é necessário aprofundamento da atividade cognitiva. Não se cuida de negativa nem de incompletude da prestação jurisdicional, mas de mera postergação da solução da parte do mérito ainda pendente do necessário amadurecimento. 
9. O sistema brasileiro consente a formação gradual da coisa julgada, com a imunização, em momentos distintos, dos diferentes capítulos decisórios de mérito exarados no processo. Necessária a revisão, pelo Superior Tribunal de Justiça, do entendimento consagrado nos precedentes à base da Súmula n. 401 .

10. O risco de contradição lógica entre as diferentes decisões decorrentes do fracionamento, do ponto de vista das respectivas fundamentações, não deve impedir o uso da técnica. Esse risco, sobre ser reduzido ante o grau de cognição exauriente que lastreia a decisão, já é inerente ao sistema, falando por si o caso do recurso parcial. Por outro lado, o instituto da coisa julgada tem por finalidade eliminar a possibilidade de conflito prático entre decisões, evitando o choque entre os preceitos imperativos extraídos de diferentes provimentos jurisdicionais. A hipotética divergência dos motivos de duas sentenças, sem conflito prático entre seus dispositivos, é admitida pelo sistema.

11. Mesmo que se entenda que o artigo $162, \S 1^{\circ}$, do Código, não serve para autorizar, como cláusula geral, a prolação de mais de uma decisão de mérito no mesmo processo, o fato é que nosso modelo processual não se coaduna com dilações indevidas. Deve o juiz, se necessário, adaptar o procedimento para exarar desde logo a decisão a respeito da parte já madura do objeto litigioso, com a sua redução naquela exata medida.

12. O temor relacionado ao caos no sistema recursal não se justifica a ponto de impedir o uso da técnica do fracionamento. Se a admissão do desmembramento enseja novas questões, sobretudo no tocante ao recurso cabível e à forma de seu processamento, elas devem ser resolvidas pela doutrina e jurisprudência, mas sem tolher o juiz, terminantemente, da possibilidade de desacumulação, com todos os benefícios que isso pode trazer em termos de encurtamento da litispendência.

13. A partir do momento em que a Constituição assegura o direito a um processo sem dilações indevidas, agregando aplicabilidade imediata a esse postulado $\left(\mathrm{CF}\right.$, art. $\left.5^{\circ}, \S 1^{\circ}\right)$, torna-se inconcebível que o juiz possa adiar a solução da parcela do mérito já suficientemente amadurecida, sobrestando a sua decisão à maturação do objeto litigioso remanescente. Deixar sem decisão uma parte já madura do objeto litigioso, aguardando que 
seja realizada a instrução relativa aos capítulos remanescentes, totalmente independentes, implica submeter o titular da situação de vantagem a um retardo inútil, configurando-se essa demora como tempo patológico do processo. O modelo processual constitucional impõe a admissão da técnica, não podendo o Estado-Juiz escorar-se na alegada deficiência da legislação processual para postergar o reconhecimento e satisfação do direito já demonstrado.

14. Os casos de cumulação simples constituem o ambiente mais fértil e propício para a aplicação da técnica do desmembramento. Porém, ela pode também ter aplicação nos demais casos de cumulação, inclusive nas modalidades de cumulação imprópria.

15. Relativamente à cumulação subjetiva, a possibilidade e viabilidade do emprego da técnica do fracionamento haverá de ser aferida à luz da espécie de cumulação de pedidos proporcionada pelo litisconsórcio. Nos casos de unitariedade do litisconsórcio, sendo imperiosa a emissão de decisão idêntica para todos os litisconsortes, torna-se logicamente inviável o fracionamento. O objeto litigioso deverá ser definido simultaneamente e de modo uniforme para todos, vetando-se a segmentação da resposta judiciária.

16. Não parece coerente com o sistema o julgamento seccionado dos fundamentos da ação ou da defesa, sem a simultânea definição, total ou parcial, do mérito. $O$ exame das questões de mérito deve ser reservado para as sentenças, que em nosso entendimento poderão ser plúrimas, ferindo por etapas o objeto litigioso que se apresente complexo ou decomponível, conforme o diferente estágio de maturação das diferentes frações do mérito. Para as interlocutórias ficará reservada a solução de demandas incidentes, viabilizando a marcha do processo e preparando o caminho para a ulterior prolação da sentença.

17. À semelhança da figura do julgamento antecipado da lide, a cisão do objeto litigioso não é medida deixada ao alvedrio ou discrição do magistrado, mas autêntico poder-dever seu, de tal sorte que, presentes os respectivos requisitos, o juiz nada tem a fazer a não ser exarar a decisão definitiva. Não se cuida de ato discricionário.

18. Cindido o objeto litigioso, não há regra absoluta quanto ao momento em que o juiz deverá deliberar sobre o custo financeiro do processo. Regra geral essa deliberação ficará 
reservada para a sentença final, ocasião em que o juiz terá condições de, examinando globalmente a solução dada ao objeto litigioso, aferir o grau de sucumbimento de cada parte. Por vezes, no entanto, esse princípio geral sofre mitigação, autorizando o juiz a deliberar por etapas quanto aos encargos sucumbenciais, o que se dá fundamentalmente quando não há relação de dependência alguma entre a parte do mérito precedentemente julgada e o restante deixado para exame na sentença final.

19. Exarada sentença parcial, sujeitar-se-á a apelação interposta nos próprios autos em que encartada a decisão impugnada, os quais, após o juízo de admissibilidade e a abertura de oportunidade para as contrarrazões, deverão subir ao tribunal ad quem. Para que o feito possa prosseguir sem solução de continuidade no tocante à instrução e decisão do(s) pedido(s) remanescente(s), portanto sem retardo indevido da prestação jurisdicional, devem ser formados ex officio autos suplementares, que permanecerão em primeiro grau para essa finalidade. Criar-se-á instrumento semelhante a uma carta de sentença, enquanto os autos originais subirão ao tribunal, de maneira análoga ao que ocorre nas hipóteses de execução provisória da sentença sujeita a apelação sem efeito suspensivo.

20. A massificação do processo eletrônico, com a sua implantação nos mais distantes rincões do país, tende a eliminar a necessidade de formação de instrumento, autos suplementares ou de cartas de sentença. Uma vez implementado o processo eletrônico, não haverá dificuldade prática a que o processo prossiga em primeiro grau, visando à instrução e julgamento do objeto litigioso remanescente, ao mesmo tempo em que seja processada e julgada a apelação perante o órgão ad quem.

21. Necessário, ante o dissenso instaurado e até que sobrevenha lei regulando expressamente a matéria - como pretende fazer o Novo Código de Processo Civil -, que seja conferida larga aplicação ao princípio da fungibilidade recursal na espécie. A postura inflexível de não conhecer de apelação, quando boa parte da doutrina considera ser este o meio recursal adequado à impugnação do pronunciamento que fere parcialmente o mérito, equivale a expor o jurisdicionado a armadilha.

22. Possível a formação de coisa julgada sobre os plúrimos capítulos de mérito em ocasiões diferentes. O fato de subsistir o processo para o exame e julgamento de outra 
pretensão, completamente autônoma e independente daquela já decidida (com o exaurimento dos recursos interponíveis), não impede e nem interfere na estabilização dessa última. Nem mesmo o pronunciamento acerca de temas de ordem pública ou cognoscíveis de ofício terá o condão de impactar e infirmar a solução atribuída ao capítulo já estabilizado, o qual só será suscetível de ataque e modificação, teoricamente, em sede de ação rescisória.

23. O início do prazo decadencial do artigo 495, do Código de Processo Civil, independe da definição da integralidade do objeto litigioso, sendo perfeitamente possível cogitar da fluência de prazo para a rescisória mesmo na pendência do processo do qual proveio a decisão rescindenda.

24. Uma vez passada em julgado a sentença parcial (ou resolução interlocutória de mérito) - pela não interposição de recurso ou pelo esgotamento dos recursos cabíveis -, teremos aí um título executivo definitivo, afastando, conseguintemente, o regime do artigo 475-O, do Código de Processo Civil, para a fase de cumprimento.

25. Influenciado pelo Substitutivo do IBDP, o Projeto do Novo Código de Processo Civil, aprovado na Câmara e pendente de revisão pelo Senado Federal, contempla expressamente o instituto do "Julgamento Antecipado Parcial do Mérito", entre as hipóteses de julgamento conforme o estado do processo. Admite-se a definição de parte do mérito via interlocutória, possibilidade autorizada em termos amplos, incidindo não apenas nos casos de incontrovérsia parcial, mas sempre que, encontrando-se suficientemente amadurecida certa fração do mérito, não houver necessidade de produção de outras provas para o seu julgamento. 


\section{BIBLIOGRAFIA}

AMBRIZZI, Tiago Ravazzi. "Reflexões sobre o controle judicial da sentença arbitral". Revista de Processo, Vol. 214, Dezembro de 2012, pp. 299 e seguintes.

AMERICANO, Jorge. Código de Processo Civil do Brasil. 2a Ed. São Paulo: Saraiva, 1958.

AMORIM FILHO, Agnelo. "Critério científico para distinguir a prescrição da decadência e para identificar as ações imprescritíveis". Revista dos Tribunais, Vol. 744, Outubro de 1997, pp. 725 e seguintes.

AMORIM, José Roberto Neves. Coisa julgada parcial no processo civil. Tese (Doutorado em Direito Processual) - Faculdade de Direito, Pontifícia Universidade Católica de São Paulo, São Paulo, 2009.

ANDRADE, Érico. "As novas perspectivas do gerenciamento e da contratualização do processo". Revista de Processo, Vol. 193, Março de 2011, pp. 167 e seguintes.

ARAÚJO, José Henrique Mouta. Coisa julgada progressiva e resolução parcial do mérito. $1^{a}$ Ed. Curitiba: Juruá, 2011.

ARAÚJO, Luciano Vianna. Sentenças parciais? Tese (Mestrado em Direito Processual) Faculdade de Direito, Pontifícia Universidade Católica de São Paulo, São Paulo, 2010.

ARMELIN, Donaldo. "Notas sobre sentença parcial e arbitragem". Revista de Arbitragem e Mediação, Vol. 18, Julho de 2008, pp. 274 e seguintes.

ARRUDA ALVIM, Eduardo. Antecipação da Tutela. Curitiba: Juruá, 2008.

. "Notas sobre o litisconsórcio no direito processual civil brasileiro". Extraído de: http://www.arrudaalvimadvogados.com.br/visualizar- 
artigo.php?artigo $=6 \&$ data $=30 / 01 / 2011 \&$ titulo=notas-sobre-o-litisconsorcio-no-direitoprocessual-civil-brasileiro. Acesso em 18.11.2014.

ARRUDA ALVIM, José Manuel de. Manual de Direito Processual Civil. Vol. 2. $6^{\text {a }}$ Ed. S. Paulo: RT, 1997.

. "Notas sobre a disciplina da antecipação de tutela na Lei 10.444 , de 7 de maio de 2002”. Revista de Processo, Vol. 108, Outubro de 2002, pp. 105 e seguintes.

ARRUDA, Samuel Miranda. In: CANOTILHO, J. J. Gomes et al. Comentários à Constituição do Brasil. S. Paulo: Saraiva/Almedina, 2013.

ASSIS, Araken. Cumulação de ações. $1^{\text {a }}$ Ed. S. Paulo: RT, 1989.

. "Efeito Devolutivo da Apelação.” In: MAZZEI, Rodrigo Reis (Coord.). Dos Recursos. Vol. 2. Vitória: ICE, 2002, pp. 53-88. . Manual da Execução. 11ª Ed. São Paulo: RT, 2008.

AZEVEDO, Ana Paula Schoriza Bueno de. "Capítulos de sentença: como o STJ tem se posicionado sobre o termo inicial para a contagem do prazo da ação rescisória?”. Revista de Processo, Vol. 176, Outubro de 2009, pp. 195 e seguintes.

AYOUB, Luiz Roberto; PELLEGRINO, Antônio Pedro. “A sentença parcial”. Revista de Arbitragem e Mediação, Vol. 22, Julho de 2009, pp. 33 e seguintes.

BARBOSA, Bruno Valentim. Julgamentos parciais de mérito no processo civil individual brasileiro. Tese (Mestrado em Direito Processual) - Faculdade de Direito, Universidade de São Paulo, São Paulo, 2013.

BARBOSA MOREIRA, José Carlos. “A nova definição de sentença”. Temas de Direito Processual (Nona Série). S. Paulo: Saraiva, 2007, pp. 167-178. 
. Comentários ao Código de Processo Civil. Vol. V. R. Janeiro: Forense, 2002.

. “Correlação entre o pedido e a sentença". Revista de Processo, Vol. 83, Julho de 1996, pp. 207 e seguintes.

"Sentença objetivamente complexa, trânsito em julgado e rescindibilidade". Revista de Processo, Vol. 141, Novembro de 2006, pp. 7 e seguintes.

BARBOSA, Rui. Oração aos Moços. Extraído de: http://www.casaruibarbosa.gov.br/dados/DOC/artigos/rui_barbosa/FCRB_RuiBarbosa_Or acao_aos_mocos.pdf. Acesso em 07.11.2014.

BARROS, Hamilton de Moraes e. Comentários ao Código de Processo Civil. Vol. IX. $2^{\text {a }}$ Ed. R. de Janeiro: Forense, 1980.

BATISTA LOPES, João. "Breves considerações sobre o instituto da preclusão". Revista de Processo, Vol. 23, Julho de 1981, pp. 45 e seguintes.

BEBBER, Júlio César. "Recurso parcial e formação gradual da coisa julgada sob enfoque dos capítulos de sentença". Revista de Direito do Trabalho, Vol. 134, Abril de 2009, pp. 150 e seguintes.

BEDAQUE, José Roberto dos Santos. “Algumas considerações sobre o cumprimento da sentença condenatória". Revista do Advogado, AASP, Vol. 85, Maio de 2006, pp. 63-77.

. Direito e Processo. 2a Ed. São Paulo: Malheiros, 1997.

. In: MARCATO, Antonio Carlos (Coord.). Código de Processo Civil interpretado. S. Paulo: Atlas, 2004.

. "Os elementos objetivos da demanda examinados à luz do contraditório". In: TUCCI, José Rogério Cruz e; BEDAQUE, (Coord.). Causa de pedir e 
pedido no processo civil (questões polêmicas). S. Paulo: RT, 2002, pp. 13-52.

. Poderes Instrutórios do Juiz. 5 Ed. São Paulo: RT, 2011.

- Tutela cautelar e tutela antecipada: tutelas sumárias e de urgência (tentativa de sistematização). 5a Ed. São Paulo: Malheiros, 2009.

BEVILACQUA, Clovis. Theoria Geral do Direito Civil. $6^{\mathrm{a}}$ Ed. Rio de Janeiro: Editora Paulo de Azevedo, 1953.

BONÍCIO, Marcelo José Magalhães. 'Notas sobre a tutela antecipada 'parcial' na nova reforma do Código de Processo Civil". Revista dos Tribunais, Vol. 808, Fevereiro de 2003, pp. 72 e seguintes.

BOTELHO DE MESQUITA, José Ignacio. Metamorfose dos embargos. Revista do Advogado, AASP, Vol. 85, Maio de 2006, pp. 57-62.

BRONIWICZ, W.; ALVINO, E. Ricerche Sul Processo: 3 - Il processo civile polacco. Perugia: Maggioli Editore, 1981.

BUENO, Cassio Scarpinella. A Nova Etapa da Reforma do Código de Processo Civil. $2^{\mathrm{a}}$ Ed. S. Paulo: Saraiva, 2006.

. In: MARCATO, Antonio Carlos (Coord.). Código de Processo Civil interpretado. S. Paulo: Atlas, 2004.

. Curso sistematizado direito processual civil. Vol. 4. 6 ${ }^{\mathrm{a}}$ Ed. S. Paulo: Saraiva, 2014.

BUENO FILHO, Edgard Silveira. O Direito à Defesa na Constituição. S. Paulo: Saraiva, 1994.

BUZAID, Alfredo. Exposição de Motivos do Projeto do Código de Processo Civil. 
Extraído de http://www2.senado.leg.br/bdsf/bitstream/handle/id/177828/CodProcCivil\% 201974.pdf?sequence=4. Acesso em 22.10.2014.

CALMON DE PASSOS, José Joaquim. Comentários ao Código de Processo Civil. Vol. III. $6^{\text {a }}$ Ed. Rio de Janeiro: Forense, 1989.

CÂMARA, Alexandre Freitas. Lições de Direito Processual Civil. Vol. III. 12 ${ }^{\mathrm{a}}$ Ed. R. de Janeiro: Lumen Juris, 2007.

CARMONA, Carlos Alberto. "Ensaio sobre a sentença arbitral parcial”. Revista de Processo, Vol. 165, Novembro de 2008, pp. 9 e seguintes.

CARNEIRO, Athos Gusmão. "Ação rescisória, biênio decadencial e recurso parcial”. Extraído de http://www.abdpc.org.br/abdpc/artigos/Athos\%20Gusm\%C3\%A3o\%20Carneiro\%20forma tado.pdf. Acesso em 04.11.2014.

. Cumprimento da Sentença Civil. R. de Janeiro: Forense, 2007.

CARNEIRO DA CUNHA, Leonardo José. "Termo inicial do prazo para ajuizamento da ação rescisória, capítulos de sentença e recursal". Revista de Processo, Vol. 120, Fevereiro de 2005, pp. 180 e seguintes.

CARVAlHO SANTOS, J. M. Código Civil Interpretado. Vol. III. 12 ${ }^{\mathrm{a}}$ Ed. Rio de Janeiro: Freitas Bastos, 1984.

CORTEZ, Cláudia Helena Poggio. "O novo conceito de sentença visto pelos tribunais". Revista de Processo, Vol. 171, Maio de 2009, pp. 282 e seguintes.

COSTA MACHADO, Antônio Cláudio. Código de Processo Civil interpretado e anotado: artigo por artigo, parágrafo por parágrafo. Barueri: Manole, 2006.

CHIOVENDA, Giuseppe. Instituições de Direito Processual Civil. Vol. III. 2a Ed. São 
Paulo: Saraiva, 1965.

CIANCI, Mirna. In: ARMELIN, Donaldo et al. Comentários à execução civil: título judicial e extrajudicial (artigo por artigo) - de acordo com as Leis n. 11.232/2005 e 11.382/2006. São Paulo: Saraiva, 2008.

CINTRA, Antonio Carlos de Araújo; GRINOVER, Ada Pellegrini; DINAMARCO, Cândido Rangel. Teoria Geral do Processo. 17ª Ed. S. Paulo: Malheiros, 2001.

DALL'ALBA, Felipe Camilo. "Julgamento antecipado ou antecipação dos efeitos da tutela do pedido incontroverso?". Revista de Processo, Vol. 128, Outubro de 2005, pp. 207 e seguintes.

DIAS, Jean Carlos. "A configuração da coisa julgada parcial e suas repercussões processuais no âmbito do cumprimento de sentença”. Revista de Processo, Vol. 135, Maio de 2006, pp. 267 e seguintes.

DIDIER JR., Fredie. "Inovações na antecipação dos efeitos da tutela e a resolução parcial do mérito". Revista de Processo, Vol. 110, Abril de 2003, pp. 225 e seguintes.

DINAMARCO, Cândido Rangel. A Instrumentalidade do Processo. $3^{\text {a }}$ Ed. S. Paulo: Malheiros, 1993.

. A Reforma da Reforma. $6^{\text {a }}$ Ed. São Paulo: Malheiros, 2004.

. "As três figuras da liquidação de sentença". Fundamentos do Processo Civil Moderno. Tomo. II. $3^{\text {a }}$ Ed. S. Paulo: Malheiros, 2000, pp. 1233-1266.

. Capítulos de sentença. São Paulo: Malheiros, 2002.

. Instituições de Direito Processual Civil. Vol. II. S. Paulo: Malheiros, 2001 . 
. Instituições de Direito Processual Civil. Vol. II. $6^{\mathrm{a}}$ Ed. São Paulo: Malheiros, 2009.

. Instituições de Direito Processual Civil. Vol. III. São Paulo: Malheiros, 2001.

. Instituições de Direito Processual Civil. Vol. III. 6 ${ }^{\mathrm{a}}$ Ed. S. Paulo:

Malheiros, 2009.

. Instituições de Direito Processual Civil. Vol. IV. $3^{\mathrm{a}}$ Ed. São Paulo:

Malheiros, 2009.

. Intervenção de terceiros. $5^{\mathrm{a}}$ Ed. São Paulo, Malheiros, 2009.

Litisconsórcio. $8^{\text {a }}$ Ed. S. Paulo: Malheiros, 2009.

. Nova era do processo civil. $4^{\text {a }}$ Ed. S. Paulo: Malheiros, 2013.

. "O conceito de mérito em processo civil". Fundamentos do Processo Civil

Moderno. Tomo I. $3^{\text {a }}$ Ed. São Paulo: Malheiros, 2000, pp. 232-276.

. Vocabulário do Processo Civil. S. Paulo: Malheiros, 2009.

DORIA, Rogéria Dotti. “A litigância de má-fé e a aplicação de multas”. Extraído de http://www.dotti.adv.br/rogeria.pdf. Acesso em 28.10.2014.

FABRÍCIO, Adroaldo Furtado. Comentários ao Código de Processo Civil. Vol. VIII. Tomo III. $2^{\text {a }}$ Ed. Rio de Janeiro: Forense, 1984.

FERREIRA, Aurélio Buarque de Holanda. Novo Aurélio Século XXI: o dicionário da lingua portuguesa. $3^{\text {a }}$ Ed. Rio de Janeiro: Nova Fronteira, 1989.

FICHTNER, José Antonio; MONTEIRO, André Luís. "Sentença parcial de mérito na 
arbitragem”. Temas de arbitragem: Primeira Série. Rio de Janeiro: Renovar, 2010, pp. 149-188.

FLACH, Daisson. In: OLIVEIRA, Carlos Alberto Alvaro de (Coord.). A nova execução: comentários à Lei $n^{\circ}$ 11.232, de 22 de dezembro de 2005. R. de Janeiro: Forense, 2005.

FLACH, Rafael. "A súmula 401 do Superior Tribunal de Justiça e a coisa julgada progressiva". Revista de Processo, Vol. 185, Julho de 2010, pp. 175 e seguintes.

FORNACIARI JÚNIOR, Clito. Reconhecimento jurídico do pedido. S. Paulo: RT, 1977.

FREDERICO MARQUES, José. Manual de Direito Processual Civil. Vol. II. $3^{\text {a }}$ Ed. São Paulo: Saraiva, 1977.

. Manual de direito processual civil. Vol. III. $3^{\text {a }}$ Ed. S. Paulo: Saraiva, 1978.

FIGUEIRA JÚNIOR, Joel Dias. Comentários ao Código de Processo Civil. Vol. 4. Tomo II. São Paulo: RT, 2001.

FUX, Luiz. Curso de Direito Processual Civil. 2a Ed. R. de Janeiro: Forense, 2004.

GAJARDONI, Fernando da Fonseca. Flexibilização Procedimental: Um Novo Enfoque para o Estudo do Procedimento em Matéria Processual. São Paulo: Atlas, 2008.

GAMBA, Cinzia. In: CARPI, Federico; TARUFFO, Michele (Coord.). Commentario breve al Codice di Procedura Civile. 4ª Ed. Padova: Cedam, 2002.

GARCIA, Gustavo Filipe Barbosa. "Capítulos Autônomos da Decisão e Momentos de seu Trânsito em Julgado". Revista de Processo, Vol. 111, Julho de 2003, pp. 290 e seguintes.

GIANNICO, Maurício. A preclusão no direito processual civil brasileiro. S. Paulo: Saraiva, 2005. 
GOMES, Mariângela Gama de Magalhães. "Devido processo legal e direito ao procedimento adequado". Revista Brasileira de Ciências Criminais, Vol. 55, Julho de 2005, pp. 293 e seguintes.

GONÇALVES FILHO, João Gilberto. O princípio constitucional da eficiência no processo civil. Tese (Doutorado em Direito Processual) - Faculdade de Direito, Universidade de São Paulo, São Paulo, 2010.

GONÇALVES, Marcus Vinicius Rios. Novo Curso de Direito Processual Civil. Vol. 1. $3^{\mathrm{a}}$ Ed. S. Paulo: Saraiva, 2006.

. Novo Curso de Direito Processual Civil. Vol. 2. São Paulo: Saraiva, 2006.

GRECO FILHO, Vicente. Direito Processual Civil Brasileiro. $2^{\circ}$ Vol. $5^{\mathrm{a}}$ Ed. S. Paulo: Saraiva, 1992.

GRINOVER, Ada Pellegrini. Direito Processual Civil. 2a Ed. São Paulo: Bushatsky, 1975.

LEITE, Clarisse Frechiani Lara. "O conceito de sentença”. In: COSTA, Suzana Henriques da (Coord.). A Nova Execução Civil - Lei 11.232/05. S. Paulo: Quartier Latin, 2006, pp. 70-94.

LENT. Friedrich. Diritto Processuale Civile Tedesco. Parte prima. RICCI, Edoardo F. (Trad.). Morano: Napoli, 1962.

LEONEL, Ricardo Barros. "Objeto litigioso do processo e o princípio do duplo grau de jurisdição". In: TUCCI, José Rogério Cruz e; BEDAQUE, José Roberto dos Santos (Coord.). Causa de pedir e pedido no processo civil (questões polêmicas). S. Paulo: RT, 2002, pp. 343-410.

LIEBLE, Stephan. Proceso Civil Alemán. 2a Ed. Medellín: Biblioteca Jurídica Diké, 1999.

LIEBMAN, Enrico Tullio. Manual de Direito Processual Civil. Vol. I. Rio de Janeiro: 
Forense, 1984.

LUCON, Paulo Henrique dos Santos. In: MARCATO, Antonio Carlos (Coord.). Código de Processo Civil Interpretado. S. Paulo: Atlas, 2004.

. "Estabilização da tutela antecipada e julgamento parcial de mérito". Extraído de http://www.direitoprocessual.org.br/index.php?novo-cpc-2. Acesso em 22.10.2014.

. “O novo regime do agravo (Lei n. 11.187/2005)". Revista do Advogado, AASP, Vol. 85, Maio de 2006, pp. 159-173.

MAGALHÃES, José Carlos de. “A ordem das provas no processo arbitral”. In: BERTASI, Maria Odete Duque; CORREAA NETO, Oscavo Cordeiro (Coord.). Arbitragem $e$ desenvolvimento. São Paulo: Quartier Latin, 2009, pp. 52 e seguintes.

MALUF, Carlos Alberto Dabus. "Cumulação de ações no processo civil”. Revista de Processo, Vol. 17, Janeiro de 1980, pp. 61 e seguintes.

MARCATO, Antonio Carlos. In: (Coord.). Código de Processo Civil interpretado. S. Paulo: Atlas, 2004.

. Procedimentos Especiais. 12 ${ }^{\mathrm{a}}$ Ed. S. Paulo: Atlas, 2006.

MARCONDES, Fernando. "Análise dos desdobramentos da fase pericial na arbitragem". In: MAIA NETO, Francisco; FIGUEIREDO, Flavio Fernando (Coord.). Perícias em arbitragem. São Paulo: Leud, 2012, pp. 145-163.

MARINONI, Luiz Guilherme. Abuso de defesa e parte incontroversa da demanda. São Paulo: RT, 2007.

. In: CANOtilho, J. J. Gomes et al. Comentários à Constituição do Brasil. S. Paulo: Saraiva/Almedina, 2013. 
. Tutela Antecipatória e Julgamento Antecipado: Parte Incontroversa da

Demanda. 5a Ed. São Paulo: RT, 2002.

MARTINS, Sandro Gilbert. "Reflexos do novo conceito de sentença (art. 162, §1 ${ }^{\circ}$, do CPC), com a redação dada pela Lei 11.232/2005”. Revista de Processo, Vol. 163, Setembro de 2008, pp. 305 e seguintes.

MEDINA, José Miguel Garcia; WAMBIER, Teresa Arruda Alvim. Recursos e Ações Autônomas de Impugnação. São Paulo: RT, 2008.

MENDES, Gilmar Ferreira. In: ; BRANCO, Paulo Gustavo Gonet. Curso de Direito Constitucional. $9^{\text {a }}$ Ed. S. Paulo: Saraiva, 2014.

. Comentários à Constituição do Brasil. In: CANOTILHO, J. J. Gomes et al. S. Paulo: Saraiva/Almedina, 2013.

MENDONÇA LIMA, Alcides de. "Ação rescisória contra acórdão em agravo de instrumento". Revista Forense, Vol. 298, pp. 7-9.

MENDONÇA, Luís Correia de. "Processo civil líquido e garantias (O Regime Processual Experimental Português)". Revista de Processo, Vol. 170, Abril de 2009, pp. 215 e seguintes.

MITIDIERO, Daniel Francisco. In: OLIVEIRA, Carlos Alberto Alvaro de (Coord.). $A$ nova execução: comentários à Lei $n^{o} 11.232$, de 22 de dezembro de 2005. R. de Janeiro: Forense, 2005.

. "Direito fundamental ao julgamento definitivo da parcela incontroversa: uma proposta de compreensão do art. $273, \S 6^{\circ}$ do CPC, na perspectiva do direito fundamental a um processo sem dilações indevidas (art. 5, LXXVIII, da CF/1988)". Revista de Processo, Vol. 149, Julho de 2007, pp. 105 e seguintes. 
MONIZ DE ARAGÃO, Egas Dirceu. Comentários ao Código de Processo Civil, Lei $n^{o}$ 5.869, de 11 de janeiro de 1973. Vol. II. $9^{\text {a }}$ Ed. Rio de Janeiro: Forense, 1998.

MONTEIRO, Washington de Barros. Curso de Direito Civil. Vol. 1: Parte Geral. 15 $5^{\mathrm{a}}$ Ed. S. Paulo: Saraiva, 1977.

MORAES, Alexandre de. Constituição do Brasil Interpretada e Legislação Constitucional. S. Paulo: Atlas, 2002.

MUNHOZ DA CUNHA, Alcides A. "Sentenças interlocutórias desafiando apelação". Revista de Processo, Vol. 185, Julho de 2010, pp. 211 e seguintes.

NEGRÃO, Theotonio; GOUVÊA, José Roberto Ferreira. Código de Processo Civil e legislação processual em vigor. 39ª Ed. São Paulo: Saraiva, 2007.

; GOUVÊA, José Roberto Ferreira; BONDIOLI, Luis Guilherme Aidar. Código de Processo Civil e legislação processual em vigor. $43^{\mathrm{a}}$ Ed. S. Paulo: Saraiva, 2011.

NERY JR., Nelson; NERY, Rosa Maria de Andrade. Código de Processo Civil Comentado e legislação processual extravagante em vigor. $6^{\text {a }}$ Ed. S. Paulo: RT, 2002.

NEVES, Daniel Amorim Assumpção. Manual de Direito Processual Civil. Volume único.

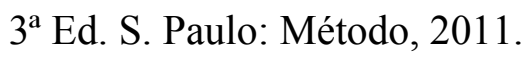
. "O novo conceito de sentença de mérito e os problemas recursais". In: BRUSCHI, Gilberto Gomes; SHIMURA, Sérgio (Coord.). Execução civil e cumprimento de sentença. Vol. 2. S. Paulo: Método, 2007, pp. 71-86.

OLIANI, José Alexandre Manzano. "Cumprimento da sentença interlocutória que condena ao pagamento de soma, de acordo com a Lei 11.232/2005.” In: SANTOS, Ernane Fidélis dos; WAMBIER, Luiz Rodrigues; NERY JR., Nelson; WAMBIER, Teresa Arruda Alvim (Coord.). Execução Civil: Estudos em homenagem ao Professor Humberto Theodoro 
Júnior. S. Paulo: RT, 2007, pp. 173-183.

OLIVEIRA, Guilherme Peres de. "Novo conceito de sentença: análise da jurisprudência acerca do recurso cabível nas situações duvidosas e aplicação do princípio da fungibilidade". Revista de Processo, Vol. 164, Outubro de 2008, pp. 164 e seguintes.

OLIVEIRA FILHO, Silas Dias de. Julgamento fracionado do mérito e suas implicações no sistema recursal. Tese (Mestrado em Direito Processual) - Faculdade de Direito, Universidade de São Paulo, São Paulo, 2013.

PEREIRA, Caio Mário da Silva. Instituições de Direito Civil. Vol. I. $6^{\text {a }}$ Ed. Rio de Janeiro: Forense, 1982.

PIETRO, Maria Sylvia Zanella Di. Direito Administrativo. 14ª Ed. S. Paulo: Atlas, 2002.

PIZZOL, Patricia Miranda. In: MARCATO, Antonio Carlos (Coord.). Código de Processo Civil interpretado. S. Paulo: Atlas, 2004.

PONTES DE MIRANDA, Francisco C. Comentários ao Código de Processo Civil. Tomo IV: arts. 282 a 443. Rio de Janeiro: Forense, 1996.

RAGONE, Álvaro J. Pérez; PRADILLO, Juan Carlos Ortiz. Código Procesal Civil Alemán (ZPO). Montevidéu: Fundación Konrad-Adenauer, Oficina Uruguay, 2006.

REDONDO, Bruno Garcia. "Sentença parcial de mérito e apelação em autos suplementares". Revista de Processo, Vol. 160, Junho de 2008, pp. 160 e seguintes.

RODRIGUES, Silvio. Direito Civil. Dos Contratos e das Declarações Unilaterais da Vontade. Vol. 3. 30 Ed. S. Paulo: Saraiva, 2002.

. Direito Civil. Parte Geral. Vol. 1. 30ª Ed. S. Paulo: Saraiva, 2002.

. Direito Civil. Parte Geral das Obrigações. Vol. 2. 30ª Ed. S. Paulo: 
Saraiva, 2002.

SANCHES, Sydney. "Objeto do processo e objeto litigioso do processo". Revista de Processo, Vol. 13, Janeiro de 1979, pp. 31 e seguintes.

SANT'ANNA, Paulo Afonso de Souza. "Sentença parcial”. Revista de Processo, Vol. 151, Setembro de 2007, pp. 151 e seguintes.

SANTOS, Moacyr Amaral. Primeiras Linhas de Direito Processual Civil. $2^{\circ}$ Vol. $3^{\text {a }}$ Ed. S. Paulo: Saraiva, 1977.

SCARANCE FERNANDES, Antonio. Incidente processual: questão incidental, procedimento incidental. S. Paulo: RT, 1991.

SCARPARO, Eduardo Kochenborger. "Sentenças parciais? Considerações a partir da reforma do art. 162, $\S 1^{\circ}$ do CPC”. Revista de Processo, Vol. 148, Junho de 2007, pp. 153 e seguintes.

SICA, Heitor Vitor Mendonça. "Algumas implicações do Novo Conceito de Sentença no Processo Civil, de Acordo com a Lei n. 11.232/2005”. In CARMONA, Carlos Alberto (Coord.). Reflexões sobre a reforma do código de processo civil: estudos em homenagem a Ada Pellegrini Grinover, Cândido R. Dinamarco e Kazuo Watanabe. S. Paulo: Atlas, 2007, pp. 186-209.

. “A nova liquidação de sentença e suas velhas questões”. In: BUENO, Cassio Scarpinella; WAMBIER, Teresa Arruda Alvim (Coord.). Aspectos Polêmicos da nova Execução. Vol. 4. S. Paulo: RT, 2008, pp. 210-239.

. Preclusão processual civil. $2^{\mathrm{a}}$ Ed. S. Paulo: Atlas, 2008.

SILVA, Ovídio Baptista da. Comentários ao Código de Processo Civil. Vol. 13. S. Paulo: RT, 2000. 
. "Decisões interlocutórias e sentenças liminares". Revista de Processo, Vol. 16, Janeiro de 1991, pp. 7-23.

SILVEIRA DE OLIVEIRA, Bruno. “A 'interlocutória faz de conta' e o 'recurso ornitorrinco' (ensaio sobre a sentença parcial e sobre o recurso dela cabível)". Revista de Processo, Vol. 203, Janeiro de 2011, pp. 73 e seguintes.

. "Um novo conceito de sentença?". Revista de Processo, Vol. 149, Julho de 2007, pp. 149 e seguintes.

SOUZA JUNIOR, Sidney Pereira de. Sentenças parciais no processo civil e suas consequências no âmbito recursal. Tese (Mestrado em Direito) - Faculdade de Direito, Pontifícia Universidade Católica de São Paulo, São Paulo, 2007.

TALAMINI, Eduardo. Coisa julgada e sua revisão. São Paulo: RT, 2005.

. “Saneamento do processo". Revista de Processo, Vol. 86, Abril de 1997, pp. 76 e seguintes.

TEIXEIRA, Guilherme Puchalski. "Sentenças objetivamente complexas: impossibilidade do trânsito em julgado parcial”. Revista de Processo, Vol. 162, Agosto de 2008, pp. 228 e seguintes.

THEODORO JÚNIOR, Humberto. As Novas Reformas do Código de Processo Civil. Rio de Janeiro: Forense, 2006.

. “Coisa julgada: pluralidade e unicidade (Súmula n. 401 do STJ).” Extraído de http://www.rkladvocacia.com/arquivos/artigos/art_srt_arquivo20130430104340.pdf. Acesso em 20.10.2014.

- "O problema da recorribilidade das interlocutórias no processo civil brasileiro". Extraído de http://www.abdpc.org.br/abdpc/artigos/Humberto \%20Theodoro \%20J\%C3\%BAnior\%20-\%20formatado.pdf. Acesso em 22.10.2014. 
TUCCI, José Rogério Cruz e. A motivação da sentença no processo civil. S. Paulo: Saraiva, 1987.

Da reconvenção: perfil histórico dogmático. São Paulo: Saraiva, 1984.

- "Garantias Constitucionais da Duração Razoável e da Economia Processual no Projeto do Código de Processo Civil”. Revista de Processo, Vol. 192, Fevereiro de 2011, pp. 193 e seguintes.

. Lineamentos da nova reforma do CPC: Lei 10.352, de 26.12.2001, Lei 10.358, de 27.12.2001. São Paulo: RT, 2002.

. "Reflexões sobre a cumulação subsidiária de pedidos". In:

BEDAQUE, José Roberto dos Santos (Coord.). Causa de pedir e pedido no processo civil (questões polêmicas). S. Paulo: RT, 2002, pp. 279-294.

. Tempo e Processo. São Paulo: RT, 1997.

VARGAS, Jorge de Oliveira. "O novo conceito de sentença e o recurso daquela que não extingue o processo: apelação ou agravo de instrumento". In: NERY JR., Nelson; WAMBIER, Teresa Arruda Alvim. Aspectos polêmicos e atuais dos recursos. Vol. 11. São Paulo: RT, 2007, pp. 152-157.

WAMBIER, Luiz Rodrigues. Liquidação de sentença. S Paulo: RT, 1997.

; WAMBIER, Teresa Arruda Alvim. "Anotações sobre a efetividade do processo". Revista dos Tribunais, Vol. 814, Agosto de 2003, pp. 63 e seguintes

; WAMBIER, Teresa Arruda Alvim; MEDINA, José Miguel Garcia. Breves Comentários à Nova Sistemática Processual Civil 2. São Paulo: RT, 2006.

; WAMBIER, Teresa Arruda Alvim. Breves comentários à $2^{a}$ fase da 
Reforma do Código de Processo Civil. $2^{\mathrm{a}}$ Ed. S. Paulo: RT, 2002.

; ALMEIDA, Flávio Renato Correia de; TALAMINI, Eduardo. Curso Avançado de Processo Civil. S. Paulo: RT, 1998.

WAMBIER, Teresa Arruda Alvim. Nulidades do processo e da sentença. $7^{\mathrm{a}}$ Ed. São Paulo: RT, 2014.

. "O agravo e o conceito de sentença". Revista de Processo, Vol. 144, Fevereiro de 2007, pp. 243 e seguintes.

. Os agravos no CPC brasileiro. São Paulo: RT, 2000.

WATANABE, Kazuo. Da cognição no processo civil. S. Paulo: RT, 1987.

YARSHELL, Flávio Luiz. Ação rescisória: juizos rescindente e rescisório. S. Paulo: Malheiros, 2005. 